\title{
Review
}

\section{A biological hypothesis: is it possible that human symbiotic microbiota coding hunger genes for human beings?}

\author{
Chenggang Zhang*, Wenjing Gong, Zhihui Li, Dawen Gao, Yan Gao \\ Institute of Radiation Medicine, Academy of Military Medical Sciences, Academy of Military Sciences, Research \\ Center for the Military Cognitive and Mental Health of PLA, Beijing 100850, China
}

*Correspondence author, ORCID: 0000-0002-4521-3304, E-mail: zhangcg@ bmi.ac.cn, zcgweb@126.com, Tel: 010-66931590, Address: Taiping Road 27, Beijing, 100850, China.

Received February 28, 2019; Accepted March 17, 2019

\begin{abstract}
The increasing number of literatures focus on the correction between symbiotic microbiota and noncommunicable diseases (NCDs) bring new light for prevention to NCDs. It is well known that the microbiota could be largely influenced by different foods, different foods will conversely influence human health. However, there still is no clue bridging the link between hunger sensation and microbiota. Based on recent research progresses between microbiota and obesity and diabetes, together with our studies, we proposed a biological hypothesis that the human symbiotic microbiota might code hunger genes for human beings. This hypothesis was supported with clinical evidences by using the flexible fasting (FF) technology. When we used the FF technology to feed the gut flora with plant polysaccharides and dietary fibers, the candidates can survive normally by using internal glycogen and fat with low or even no hunger sensation. The theory of "gut flora-centric theory (GFCT)" was then developed to explain this phenomenon. When the gut flora begins to reproduce their own offsprings in human gastrointestinal tract, they will digest and destroy the gastrointestinal mucosa to obtain the carbon sources. This signal will be transferred from gut to human brain as hunger sensation. Further efforts should focus on the mechanism underlying how and why did the symbiotic microbiota trigger and transfer the hunger sensation by activating the hunger genes. Taken together, the conjecture linking between human symbiotic microbiota and hunger sensation will probably improve prevention and control on NCDs.
\end{abstract}

Key Words: noncommunicable disease; microbiota; hunger sensation; hunger gene; gut flora-centric theory; flexible fasting; operating system

\section{Introduction}

For thousands of years we are told that we must eat food every day. It seemed to be an unalterable principle in human society, because if we did not eat food, then the formidable and uncontrolled hunger sensation will cause us die. Many diabetes patients have the experience of desperate and terrible hypoglycemia which is rather dangerous to the body. However, the Chinese old and famous proverb that "chronic diseases come from eating five kinds of grains" faintly and dimly indicated that if we did not have correct eating patterns, then we will be suffered from a large number of noncommunicable disease (NCDs). Therefore the facts "we have to eat" and "we must eat food" have been the golden laws and precious rules in our life almost from the beginning of the human history. Few people think about the origin of hunger sensation because it is one of the unalterable principles. However, when we began to ask the question that "where did the hunger sensation come from", we found that it is actually not a quite common question on the "origin of hunger sensation" and finally hypothesized that the human symbiotic microbiota probably coding the hunger genes for our human beings.

Did the hunger sensation come from gut flora?

It is well known in classical and modern genetics that "a gene

This is an open access journal, and articles are distributed under the terms of the Creative Commons Attribution-NonCommercial-ShareAlike 4.0 License, which allows others to remix, tweak, and build upon the work non-commercially, as long as appropriate credit is given and the new creations are licensed under the identical terms.

For reprints contact: weda-h@weda-h.org

How to cite this article: Zhang CG, Gong WJ, Li ZH, Gao DW, Gao Y. A biological hypothesis: is it possible that human symbiotic microbiota coding hunger genes for human beings? J Adv Health 2019; 1 (2): 145-148. 
coding for an enzyme". Almost all of the biological processions were coded by genes following the central dogmas ${ }^{1}$. This has been the law of the life science and occupying a dominant position in biological and medical science studies. When the human genome project (HGP) was successfully completed in 2000 , many scientists celebrated this great success ${ }^{2-4}$. However even after a decade, the occurrence of NCDs such as obesity and diabetes is still growing up $^{5-7}$. In case of necessity, the USA government proposed the precision medicine project ${ }^{8-10}$. However several papers published recently pointed out that there is a long to go for the precision medicine because NCDs were still out of control ${ }^{11-13}$.

During our studies, we also asked the question why there are so many NCDs in China. When a large number of literatures focused on the importance of human symbiotic microbiota with NCDs such as obesity, diabetes, hypertension, stroke, cancer, autism, depression ${ }^{14-24}$, we were also attracted by this interesting research field. Following the interesting and valuable studies of Dr. Gordon $\mathrm{JI}^{25-28}$ and Dr. Liping $\mathrm{Zhao}^{29-33}$ on the close relationship between microbiota with obesity, we began to test whether we can control the fat of our own body by controlling the gut flora. Luckily and interestingly, we finally demonstrated that when using the plant polysaccharides and dietary fibers to feed the gut flora, together with significantly reducing food intake, then the body weight can physiologically and normally reduce. These clinical studies have been published recently to support this new hypothesis ${ }^{34-37}$. This is also an important evidence to support the interesting findings of Dr. Gordon and Liping Zhao that low calorie intake and polysaccharide and dietary fiber is beneficial for health, together with the elicitation of fasting studies by Dr. Longo ${ }^{38-43}$. Based on these studies, we asked the question, is it possible that the human symbiotic microbiota coding hunger genes for human beings?

In other words, we found that although we human beings indeed did need foods to eat every day, however it seemed the hunger sensation comes from gut flora but not from the human brain itself. When the gut flora needs carbon sources and nitrogen sources to reproduce their offsprings in human gastrointestinal tract, they will digest and destroy gut mucosa and transmit the hunger sensation signals to the body, which will be transferred and transduced to our brain by vagus and neuroendocrine system ${ }^{44}$. Then the human brain will control the body to eat food to meet the food needs by gut flora. When the food was intaken after feeding, then most of the nutrients will be absorbed by the small intestine and some others will be used by gut flora. In other words, each of us need to eat, but the hunger sensation and food-eating signals were probably originated from the gut flora other than from human brain ${ }^{45-49}$.

\section{Development of the gut flora-centric theory (GFCT)}

Regarding the clinical evidences to support this hypothesis that "human symbiotic microbiota coding hunger genes for human beings", we have demonstrated that when we control the hunger sensation and food-eating signals by using the flexible fasting (FF) technology by feeding the gut flora with plant polysaccharides and dietary fibers but no food for human body, then the human body will have a special status similar like the camel living in desert. The human body can physiologically decompose the internal glycogen and fat to provide energy for the body. The candidates can then normally and healthily live for 7-14 days by only feeding the gut flora and drinking enough water everyday but without food for human body. The clinical evidences were obtained from several hospitals to provide direct support on the hypothesis that "hunger sensation comes from gut flora" and have been published in recent years ${ }^{34-37,45-53}$. Only when based on these important facts, can we realize that the hunger genes of the human beings seemed to not be coded by human genomic DNA systems, but by the genes of the human symbiotic microbiota especially the symbiotic microbiota (gut flora). Therefore, this new hypothesis will probably contribute on the updates of current knowledge on eating behavior from fundamental and essential level, which means that the current textbook will probably need to be updated in near future. As a large number of NCDs were caused by unhealthy eating patterns, most of the NCDs will then be improved by precisely targeting the abnormal gut flora based on the gut flora-centric theory (GFCT).

Frankly speaking, before our GFCT studies, almost all of the efforts looking for the hunger genes are focusing on human genes such as leptin and ghrelin ${ }^{5-56}$. It is really not easy and rather difficult for people to pay attention on the possibility that symbiotic microbiota coding hunger genes for human beings. It is also of great interests to ask why the nature place the hunger genes in microbiota other that the human genomic DNA systems. We suggested it is probably a law of the nature because the gastrointestinal tracts of the human beings are best place for the symbiotic microbiota to reproduce their offsprings. This phenomenon could also be recognized with the meaning of animal evolution as we recently reported ${ }^{57}$. It might probably be another central dogmas of life science that the symbiotic microbiota driving the evolution of animals and human beings by coding the hunger genes to "teach" the animals and human being to eat food for living ${ }^{57}$. We will discuss this perspective in further works.

\section{Future works beyond the GFCT theory}

As described in Dickens' famous and classic literary of "A tale of Two Cities", although this is the worst of times because of the out of control of NCDs worldwide, however, our current hypothesis that "human symbiotic microbiota coding hunger genes for human beings" might bring new light on the prevention and control of NCDs. Future works should focus on the identification of the spirit-needing genes (if existed) that was coded by the OS/3 (the $3^{\text {rd }}$ operating system, also named as human language and consciousness system), where the symbols, abstraction, logic, and reasoning are the basic coding processing similar as the "A, C, G, and T" bases in the OS/1 (the $1^{\text {st }}$ DNA-OS as the human genomics) and OS/2 (the $2^{\text {nd }}$ DNA-OS as human symbiotic microbiota), while the reasoning, thinking and judgment constitute the world of consciousness, mental, mind and spirit. Based on these new explanations of human body as well as the consciousness coding systems (OS/3), we will probably have a new understanding of the nature and the world to enjoy the forthcoming human life in the future.

\section{Conclusion}

To find the genes coding for hunger sensation is of great importance for human beings. In this short review, we briefly introduced the new hypothesis that the human symbiotic microbiota coding hunger genes for human beings with clinical 
evidences coupled with logical reasoning analysis. As a new hypothesis, further works are needed to address the underlying molecular mechanisms. We expected as a new begin by focusing on the symbiotic microbiota coding hunger genes for human beings, the NCDs will probably have a new chance by precisely targeting the mysterious and amazing symbiotic microbiota in human gut.

\section{Declarations}

\section{List of abbreviations}

FF: flexible fasting; GFCT: gut flora-centric theory; NCD: noncommunicable disease; OS: operating system

\section{Ethics approval and consent to participate}

Not applicable.

\section{Consent for publication}

Not applicable.

\section{Availability of data and material}

Data sharing not applicable to this article as no datasets were generated or analyzed during the current study.

\section{Funding}

This work was supported by the National Basic Research Project (973 program, 2012CB518200); General Program (81371232, 81573251) of the Natural Science Foundation of China; Special Key Programs for Drug R\&D of China (2012ZX09102301-016, 2014ZX09J14107-05B); Foundation of Joint Research Center for Translational Medicine between Beijing Proteome Research Center and Tianjin Baodi Hospital (TMRC201301).

\section{Authors' contributions}

CZ proposed the hypothesis and finalized the manuscript. WG, ZL, DG and YG provided valuable suggestion on the manuscript.

\section{Acknowledgements}

Not applicable.

\section{Competing interests}

The authors declare that they have no competing interests.

\section{REFERENCES}

1. Crick F. Central dogma of molecular biology. Nature 1970; 227 (5258): 561-563.

2. Bentley DR. Decoding the human genome sequence. Human molecular genetics 2000; 9 (16): 2353-2358.

3. Wadman M. Human Genome Project aims to finish 'working draft' next year. Nature 1999; 398 (6724): 177.

4. Waterston R, Sulston JE. The Human Genome Project: reaching the finish line. Science 1998; 282 (5386): 53-54.
5. Demaio A, Jamieson J, Horn R, de Courten M, Tellier S. Noncommunicable diseases in emergencies: a call to action. PLoS currents $2013 ; 5$.

6. Jakovljevic MB, Milovanovic O. Growing Burden of Non-Communicable Diseases in the Emerging Health Markets: The Case of BRICS. Frontiers in public health 2015; 3: 65.

7. Weil AR. The Growing Burden Of Noncommunicable Diseases. Health affairs 2015; 34 (9): 1439.

8. Carrasco-Ramiro F, Peiro-Pastor R, Aguado B. Human genomics projects and precision medicine. Gene therapy 2017; 24 (9): 551-561.

9. Konig IR, Fuchs O, Hansen G, von Mutius E, Kopp MV. What is precision medicine? The European respiratory journal 2017; 50 (4).

10. Mata DA, Katchi FM, Ramasamy R. Precision Medicine and Men's Health. American journal of men's health 2017; 11 (4): 1124-1129.

11. Coote JH, Joyner MJ. Is precision medicine the route to a healthy world? Lancet 2015; 385 (9978): 1617.

12. Prasad V. Perspective: The precision-oncology illusion. Nature 2016; 537 (7619): S63.

13. Tannock IF, Hickman JA. Limits to Personalized Cancer Medicine. The New England journal of medicine 2016; 375 (13): 1289-1294.

14. Fujimura KE, Slusher NA, Cabana MD, Lynch SV. Role of the gut microbiota in defining human health. Expert review of anti-infective therapy 2010; 8 (4): 435-454.

15. Gevers D, Knight R, Petrosino JF, Huang K, McGuire AL et al. The Human Microbiome Project: a community resource for the healthy human microbiome. PLoS biology 2012; 10 (8): e1001377.

16. Integrative HMPRNC. The Integrative Human Microbiome Project: dynamic analysis of microbiome-host omics profiles during periods of human health and disease. Cell host \& microbe 2014; 16 (3): 276-289.

17. Kramer P, Bressan P. Humans as Superorganisms: How Microbes, Viruses, Imprinted Genes, and Other Selfish Entities Shape Our Behavior. Perspectives on psychological science : a journal of the Association for Psychological Science 2015; 10 (4): 464-481.

18. Lewis CM, Jr., Obregon-Tito A, Tito RY, Foster MW, Spicer PG. The Human Microbiome Project: lessons from human genomics. Trends in microbiology 2012; 20 (1): 1-4.

19. Malkki H. Stroke: Gut microbiota influence stroke recovery in mice. Nature reviews Neurology 2016; 12 (5): 252.

20. Wen SW, Wong CHY. An unexplored brain-gut microbiota axis in stroke. Gut microbes 2017; 8 (6): 601-606.

21. Winek K, Meisel A, Dirnagl U. Gut microbiota impact on stroke outcome: Fad or fact? Journal of cerebral blood flow and metabolism : official journal of the International Society of Cerebral Blood Flow and Metabolism 2016; 36 (5): 891-898.

22. Dao MC, Clement K. Gut microbiota and obesity: Concepts relevant to clinical care. European journal of internal medicine 2018; 48: 18-24.

23. Patterson E, Ryan PM, Cryan JF, Dinan TG, Ross RP, et al. Gut microbiota, obesity and diabetes. Postgraduate medical journal 2016; 92 (1087): 286-300.

24. Torres-Fuentes C, Schellekens H, Dinan TG, Cryan JF. The microbiota-gut-brain axis in obesity. The lancet Gastroenterology of hepatology 2017; 2 (10): 747-756.

25. Backhed F, Ding H, Wang T, Hooper LV, Koh GY, et al. The gut microbiota as an environmental factor that regulates fat storage. Proceedings of the National Academy of Sciences of the United States of America 2004; 101 (44): 15718-15723.

26. Turnbaugh PJ, Backhed F, Fulton L, Gordon JI. Diet-induced obesity is linked to marked but reversible alterations in the mouse distal gut microbiome. Cell host \& microbe 2008; 3 (4): 213-223.

27. Turnbaugh PJ, Hamady M, Yatsunenko T, Cantarel BL, Duncan A et 
al. A core gut microbiome in obese and lean twins. Nature 2009; 457 (7228): 480-484.

28. Turnbaugh PJ, Ley RE, Mahowald MA, Magrini V, Mardis ER et al. An obesity-associated gut microbiome with increased capacity for energy harvest. Nature 2006; 444 (7122): 1027-1031.

29. Fei N, Zhao L. An opportunistic pathogen isolated from the gut of an obese human causes obesity in germfree mice. The ISME journal 2013; 7 (4): $880-884$

30. Zhang $\mathrm{X}$, Zhao $\mathrm{Y}, \mathrm{Xu}$ J, Xue Z, Zhang $\mathrm{M}$ et al. Modulation of gut microbiota by berberine and metformin during the treatment of high-fat diet-induced obesity in rats. Scientific reports 2015; 5: 14405.

31. Zhao L. The gut microbiota and obesity: from correlation to causality. Nature reviews Microbiology 2013; 11 (9): 639-647.

32. Zhao L, Shen J. Whole-body systems approaches for gut microbiota-targeted, preventive healthcare. Journal of biotechnology 2010; 149 (3): 183-190.

33. Hvistendahl M. My microbiome and me. Science 2012; 336 (6086): 1248-1250.

34. Gong W, Huang Q, Gao D, Qu W, Li Z, et al. Application of flexible abrosia for body weight control among youths. Military Medicine 2016; 40 (8): 651-656.

35. Gong W, Sun C, Teng S, Gao D, Li Z, et al. Evaluation of a novel fasting approach using plant polysaccharides per meal in human symbionts. Int Clin Med 2018; 2 (1): 1-12.

36. Huang Q, Teng S, Gao D, Dong H, Sha J, et al. Emergency plans of flexible abrosia to raise efficiency in disaster rescue. Disaster Medicine and Rescue (Electronic Edition) 2015; 4 (2): 81-85.

37. Ren Q, Huang J, Huang R, Liang L, Chen K, et al. Preliminary study on flexible abrosia technology to improve hypertension. Food and Nutrition in China 2017; 23 (8): 70-75.

38. Brandhorst S, Harputlugil E, Mitchell JR, Longo VD. Protective effects of short-term dietary restriction in surgical stress and chemotherapy. Ageing research reviews 2017; 39: 68-77.

39. Buono R, Longo VD. Starvation, Stress Resistance, and Cancer. Trends in endocrinology and metabolism: TEM 2018; 29 (4): 271-280.

40. Lee C, Longo VD. Fasting vs dietary restriction in cellular protection and cancer treatment: from model organisms to patients. Oncogene 2011; 30 (30): 3305-3316.

41. Longo VD, Mattson MP. Fasting: molecular mechanisms and clinical applications. Cell metabolism 2014; 19 (2): 181-192.

42. Longo VD, Panda S. Fasting, Circadian Rhythms, and Time-Restricted Feeding in Healthy Lifespan. Cell metabolism 2016; 23 (6): 1048-1059.

43. Wei M, Brandhorst S, Shelehchi M, Mirzaei H, Cheng CW et al. Fasting-mimicking diet and markers/risk factors for aging, diabetes, cancer, and cardiovascular disease. Science translational medicine 2017; 9 (377)

44. Sandhu KV, Sherwin E, Schellekens H, Stanton C, Dinan TG, et al.
Feeding the microbiota-gut-brain axis: diet, microbiome, and neuropsychiatry. Translational research : the journal of laboratory and clinical medicine 2017; 179: 223-244.

45. Zhang C. New medicine and bacteriocentric theory and a revolution in prevention and control of chronic diseases. Science \& Technology Review 2015; 33 (22): 106-111.

46. Zhang C. Enlightenment on Youyou Tu winning the Nobel Prize on R\&D of artemisinin. Science \& Technology Review 2015; 33 (20): 86-89.

47. Zhang C. New medicine, gut flora-centric theory and cloud hospital. Beijing: The Ancient Books Publishing House on Traditional Chinese Medicine; 2016.

48. Zhang C. The Gut Flora-Centric Theory Based on the New Medical Hypothesis of "Hunger Sensation Comes from Gut Flora": A New Model for Understanding the Etiology of Chronic Diseases in Human Beings. Austin Intern Med 2018; 3 (3): 1-7.

49. Zhang C, Gong W. Discovery based on hunger sensation comes from gut flora: Breakthrough in chronic disease prevention and control. Science \& Technology Review 2017; 35 (21): 43-48.

50. Zhang C. Human microecology, especially gut microflora provides unprecedented opportunities and challenges for new drug research and development. Chin J Pharmacol Toxicol 2016; 30 (7): 703-713.

51. Zhang C, Gong W. Flexible bigu: a new approach for improving obesity and related chronic diseases. Medical Journal of Chinese People's Health 2018; 30 (6): 100-102.

52. Zhang C, Gong W, Li Z, Gao D, Gao Y. Medical science version 3.0 (MS3.0) and health care management version 2.0 (HCM2.0) will significantly promote the strategy of healthy China. E-J Transl Med 2018; 5 (12): 108-124.

53. Gao D, Gong W, Li Z, Zhang C. Preliminary Research on Flexible Abrosia on High Blood Glucose of Early Stage Diabetes. Food and Nutrition in China 2018; 24 (4): 5.

54. Cui H, Lopez M, Rahmouni K. The cellular and molecular bases of leptin and ghrelin resistance in obesity. Nature reviews Endocrinology 2017; 13 (6): 338-351.

55. Ghomraoui FA, Alotaibi ST, Alharthi MA, Asiri SS, Almadi MA, et al. Plasma ghrelin and leptin in patients with inflammatory bowel disease and its association with nutritional status. Saudi journal of gastroenterology : official journal of the Saudi Gastroenterology Association 2017; 23 (3): 199-205.

56. Yavuz Y, Kumral ZN, Memi G, Cevik OD, Yegen C, et al. Serum Leptin, Obestatin, and Ghrelin Levels and Gastric Emptying Rates of Liquid and Solid Meals in Non-obese Rats with Roux-en-Y Bypass Surgery or Prosthesis Placement: Implications for the Role of Vagal Afferents. Obesity surgery 2017; 27 (4): 1037-1046.

57. Zhang C, Gong W, Li Z, Gao D, Gao Y. Gut flora-centric theory of evolution: A new model for understanding the evolution of animals. Chinese Journal of Bioinformatics 2018; 16 (4): 203-213. 